\title{
Study on Career Planning of Chinese College Students Based on Online Recruitment Information
}

\author{
Fang Cheng \\ School of Business, Anyang Normal University, Anyang, China \\ Email: chengf_tina@163.com
}

How to cite this paper: Cheng, F. (2017) Study on Career Planning of Chinese College Students Based on Online Recruitment Information. Creative Education, 8, 2455-2462. https://doi.org/10.4236/ce.2017.815168

Received: December 5, 2017

Accepted: December 19, 2017

Published: December 22, 2017

Copyright $\odot 2017$ by author and Scientific Research Publishing Inc. This work is licensed under the Creative Commons Attribution International License (CC BY 4.0).

http://creativecommons.org/licenses/by/4.0/ (c) (i)

Open Acces

\begin{abstract}
The scientific career planning of undergraduates is an important measure to promote the employment of Chinese college students and alleviate the shortage of enterprises. It is also the key measure of the "supply side" reform of Chinese higher education. This paper analyzes the feasibility and mechanism of career planning for Chinese college students based on online recruitment information. Taking the human resources management major as an example, the content analysis method based on online recruitment information is used to study Chinese college students' career development path, job quality requirements and career planning stage Determine, and use dynamic network recruitment information using rolling planning method to carry out college career planning.
\end{abstract}

\section{Keywords}

College Students Career Planning, Online Recruitment Information, Rolling Plan Method

\section{Introduction}

General Secretary Xi Jinping put forward that while moderately expanding aggregate demand, efforts should be made to strengthen supply-side structural reforms, focus on improving the quality and efficiency of the supply system and enhancing the driving force for sustained economic growth. Economic reforms inevitably lead to educational reform (Liu, 2015), of which supply-side reform of higher education is the key (Li, 2016; Cai, 2016). According to the data released by the Ministry of Education, there will be 7.95 million graduates of ordinary 
colleges and universities in China in 2016, however, a large number of Chinese enterprises have the phenomenon of "shortage of labor" and the result is unsatisfactory from the present situation of "supply side" of higher education. Career planning in the "supply side" reform of higher education in China is considered to be an important measure for the dual pressures of graduates' employment and employment shortage. However, college students consider career planning important but lack relevant career planning knowledge (Jiang, Li, Yan, \& Mo, 2015). In the past, the research on the career planning of college students focused on the problems and countermeasures (Chen, 2012), college students' employment ability or employment ability analysis (Jin, 2012; Li, 2012; Feng \& Zhang, 2011; Shi \& Wen, 2012) and college career system construction (Huang, 2012; Zhang, 2012), strong commonality, but for Chinese students, lacking of practicality. This article will use online recruitment information as an embedding point to introduce how to determine career paths, job competencies, career planning stages and how to implement career planning for college students in China.

\section{Feasibility of Career Planning of Chinese College Students Based on Online Recruitment Information}

College students' career planning, it is on the basis of self-awareness, professional and ability, combining with the social environment and market environment, in the future to engage in professional and career goals to achieve by the end of the direction of the do plan. The career planning of college students has a fundamental and long-term impact on the employment and future career development of college students. At present, there are many problems in the career planning of college students. The most prominent of these are the students' inability to obtain information on the qualities required by the positions of employers. Though universities and students could understand the employment status of employers through internship and investigation of enterprises, they could not fully study the key qualities of employing units. In the rapid development of information technology in China today, especially in the development of network technology, the network provides detailed information on job, organization and area for students' employment. The network has become an important platform for various enterprises to release recruitment information. For example, in 2015, Statistical Report on the Internet Development in China shows that enterprises use the Internet for online recruitment rate of 53.8\%; published information or $60.9 \%$ of timely news are at a high level. At the same time, from the perspective of the time and space of the birth of the Internet, college students have unparalleled advantages and conditions. Employers post information network and students master the computer and network technology, so that students can make full use of network recruitment information for career planning and implementation. 


\section{Career Planning of Chinese College Students Based on Online Recruitment Information}

\subsection{Online Recruitment Information Content Analysis}

There are many ways for Chinese university students to collect professional information, for example, through the research of enterprises. However, this method is costly and demanding, which is unrealistic for college students. China online recruitment advertisements are open and free to be obtained on the one hand, and the advertisements for the enterprises advertisements show the necessary conditions that the enterprises consider necessary for the positions, which are also the basic conditions for career change. Therefore, they are obtained through advertisements published on the Internet College career path information, content analysis of a large number of recruitment information (Song \& Song, 2012), to provide information for career development of college students.

Recruitment information sources are 51 job, Zhaopin recruitment network and other professional recruitment website for professional search. Job information: $\mathrm{PhD}$, master, undergraduate and so on; Experience elements: practitioners experience, work experience, etc.; knowledge elements: professional knowledge, business knowledge, etc.; professional skills: teamwork, learning, innovation and other capabilities; personality traits Confidence, steadiness, integrity and so on.

\subsection{Career Planning of Chinese College Students Based on Online Recruitment Information}

The most crucial career planning is the target position and career development path, job responsibilities and qualifications at different levels of positions and career planning stage. Target positions and career paths are the path through which college students identify a broad set of professional goals based on their major or hobby, ranging from the lowest level to the highest level in their area of expertise. These are available directly from the search engines on the job site. Job responsibilities and qualifications at different levels need to employ descriptive analysis or principal component analysis from the recruitment information collected from various recruitment websites to obtain the most important common factor or the highest requirement factor for enterprises in different industries and sizes. And then connecting the professional development required by each job, it is equivalent to a complete career development track from the early career development to the end of career development. For example, the path of career development of HR majors is, in descending order, HR mangers, HR mangers and managers, and HR mangers. Of course, changes may also be made at different scales or enterprises. Since a business advertisement shows the necessary job requirements that the business believes to be competent for the business, the more frequent requirements that appear in any job advertisement can be considered as the more important job requirements for the business. Through the human resources management of various job advertisements post qualification 
information collection, and content analysis, you can get a complete career path and key qualities. The length of job requirements in job advertisements can be used as the basis for the division of college students in the medium and long-term planning stages.

\section{Empirical Study on Career Planning of Chinese Undergraduates Based on Internet Recruiting Information}

\subsection{Job and Career Development Path}

Human resources management professionals corresponding positions in the online recruitment of search engines to get, and its career development path in the company development path roughly human resources at the lowest level $\rightarrow$ human resources middle level $\rightarrow$ human resources high-level positions. Personnel assistant/commissioner is the starting point for lowest-level human resources management professional job positions, short-term career planning for college students. Other middle and senior positions are the medium-term and medium-term planning of university students.

\subsection{The Job Requirements of University Students Quality Requirements}

\subsubsection{Sample Selection}

51 job is a large number of job information publishing platform ,which is China's leading multi-media resource advantages of professional human resources service agencies, recruitment data is rich and extensive, with some representation, so as the study Sample collection information platform. The data collection was conducted from August 7, 2015 to October 7, 2015. The industry was selected in the medical/nursing/health care industry to collect information from personnel assistants or personnel commissioners at the at the lowest-level position of human resource management graduates. According to the 51 job senior search, 958 job advertisements were obtained, 381 job advertisements were effectively recruited after removing job repetitions, non-personnel jobs and lack of qualified qualifications.

\subsubsection{Phrase Screening and Quality Definition}

In the advertisement of advertisements, the expressions of abilities may express different words, but the meanings are very similar. Therefore, in the process of data processing, through the process of merging and arranging phrases with similar meanings, such as "word processing, expression, good writing skills, Ability to write a document, a certain writing skills "merged into a word processing ability;" proficiency in office software, with basic knowledge of the network, human resources management software, "merged into office software capabilities; recruitment advertisement" employee labor contract, society Security, attendance, entry, leave and other formalities" merged into personnel processes. Finally, the classification of these indicators, divided into the quality 
requirements of job advertisements is divided into knowledge elements, professional skills, personality traits.

\subsection{Human Resource Management Basic Level of Job Quality Survey Results}

Through the statistical analysis of the recruitment information, the results are as follows:

1) Knowledge elements

For enterprises, knowledge of at the lowest-level positions in human resources management plays an important role in human resources management. From the statistical data (Table 1), it can be seen that the most important knowledge at the at the lowest-level is the recruitment and selection of personnel, Personnel processes, labor laws and regulations, staff training and so on.

2) Professional skills elements

Professional skills is to complete the work of human resources management at the lowest-level position job skills necessary, the specific statistical analysis results shown in Table 2. From the statistical analysis, we can see that communication ability, office software operation ability, organization and coordination, and teamwork ability are the most important enterprises' ability, followed by words and language ability.

3) Personality traits elements

Personality trait is the intrinsic quality of human resources management personnel, which promotes the promotion of all aspects of human resources management, more and more attention by enterprises. As can be seen from the statistics in Table 3, for the lowest-level managers of human resources management, the sense of responsibility, seriousness, professional ethics, and steadiness are high.

4) The key qualities of human resource management at the lowest-level position

The definition of important weights greater than the average as an important quality, so that most businesses need is essential for the development of students' career development, and thus come to human resources management ability to employ the key elements of the composition, as shown in Table 4.

Table 1. Knowledge elements.

\begin{tabular}{cccc}
\hline Knowledge element & Proportion (\%) & Knowledge element & Proportion (\%) \\
\hline $\begin{array}{c}\text { Human resources } \\
\text { strategy and planning }\end{array}$ & 15.49 & Personnel process & 68.77 \\
$\begin{array}{c}\text { Personnel recruitment } \\
\text { and selection }\end{array}$ & 82.41 & $\begin{array}{c}\text { Employee relations and } \\
\text { employee activities }\end{array}$ & 24.41 \\
Performance management & 21.26 & Labor and personnel regulations & 56.43 \\
Compensation management & 19.42 & Cultural construction & 4.20 \\
Employee training & 40.16 & Administration & 15.49 \\
Personnel system & 17.85 & Work analysis & 3.68 \\
Financial knowledge & 1.05 & & \\
\hline
\end{tabular}


Table 2. Professional skills elements

\begin{tabular}{cccc}
\hline Professional skills name & Proportion (\%) & Professional skills name & Proportion (\%) \\
\hline English language proficiency & 5.77 & $\begin{array}{c}\text { Organization and } \\
\text { coordination capacity }\end{array}$ & 44.88 \\
$\begin{array}{c}\text { Office software } \\
\text { operating capacity }\end{array}$ & 63.25 & Compression ability & 19.95 \\
$\begin{array}{c}\text { Communication skills } \\
\text { Teamwork }\end{array}$ & 78.78 & Execution & 13.39 \\
Writing skills & 43.57 & Service awareness & 8.92 \\
language expression skills & 20.73 & Learning ability & 8.40 \\
Planning ability & 24.41 & Resilience & 10.50 \\
Creativity & 5.78 & Human resources qualification & 2.10 \\
Analysis and judgment & 2.62 & Time management skills & 1.31 \\
& 16.27 & Digital analysis capabilities & 1.84 \\
\hline
\end{tabular}

Table 3. Personality characteristics of the survey results table.

\begin{tabular}{cccc}
\hline Personality trait name & Proportion (\%) & Personality trait name & Proportion (\%) \\
\hline Professional ethics & 30.71 & Hard working & 2.89 \\
Seriously rigorous & 51.18 & Upright & 11.02 \\
Responsibility & 60.89 & Image temperament & 6.56 \\
Affinity & 28.08 & confidence & 2.10 \\
Confidentiality & 3.67 & Dedication & 11.81 \\
Steadfast and steady & 29.92 & & \\
\hline
\end{tabular}

Table 4. The key qualities of human resource management at the lowest-level position.

\begin{tabular}{lcc}
\hline \multicolumn{1}{c}{ Types } & Number & Element \\
\hline Knowledge elements & 4 & Personnel process \\
& Labor and personnel regulations \\
& Employee training \\
Personality traits & Responsibility \\
& Seriously rigorous \\
& Professional ethics \\
& Steadfast and steady \\
& Communication skills \\
& Office software operating capacity \\
& Organization and coordination capacity \\
& Teamwork \\
& Wrofessional skill & language expression skills
\end{tabular}




\subsection{College Students Career Planning Stage}

Human Resource Management the key qualities of the at the lowest-level post are the professional goals of graduation. Students can set goals in four years according to the three major requirements and the school's teaching plan, and make plans in the short term. According to the post-graduate job requirements of different positions, undergraduate students can study the different levels of job quality requirements according to the career path, and in accordance with which the formulation of medium-term and long-term career development plan.

\section{Job Scheduling of Chinese Undergraduates Based on Web Recruiting Information}

Due to the continuous changes in employment and business environment, there are often some differences between the actual situation and the planned situation in the implementation of career planning. Therefore, it is necessary to make necessary amendments to the career planning on a regular basis. According to the principle of the rolling plan method (Wang, Peng et al., 2012), assume that the planning period is 4 years, and the annual plan is set according to the principle of finer and finer. After the plan is implemented for one year, according to the change of the recruiting information of the actual enterprise network, the annual plan is amended according to the principle of finer and finer and the plan is extended for one year later, and so on.

In addition to dynamic web recruitment information, college students need to further understand the external environment of career development by making use of such information as network industry and regional development when formulating and implementing career planning. At the same time, they should communicate with enterprise staff or human resource management managers to determine whether it is suitable for business or employment or choose their own job match, these need more follow-up attention and in-depth study.

\section{Conclusion}

Aiming at college students lack of practical skills of career planning of the status quo, recruitment information by network as a embedded point, adopts content analysis method to explore the college students' career path method, and uses the rolling planning laws implementing college students' career planning, in order to help college students to develop career planning science, to promote employment ability, finally realizes the scientific employment. Due to different professional situations, the recruitment sources involved are different, and students should find the most abundant information platform for job information according to their professional, expected employment industry and position. In this paper, there are some shortcomings in the research of the post information acquisition platform, which has been studied only at the base level, and the future needs to further enrich these contents. 


\section{References}

Cai, F. (2016). Supply-Side Reforms Require a Breakthrough in Education System Reform.

http://www.360doc.com/content/16/0106/10/5719126_525841705.shtml, 2016-1-7.

Chen, H. (2012). Vocational Students Career Planning Problems and Suggestions. Education Exploration, 3, 151-152.

Feng, H., \& Zhang, B. (2011).Research on the Current Situation and Problems of the Employment Ability of Chinese Undergraduates: Taking Beijing as an Example. Management World, 8, 175-176.

Huang, L. M. (2012). Exploration and Innovation of Vocational Guidance in Colleges and Universities. Hubei Social Sciences, 8, 181-183.

Jiang, M. L., Li, Z. G., Yan, X. F., \& Mo, J. J. (2015). College Students Career Planning Behavior Choices and Influencing Factors. Higher Education Exploration, 2, 110-116.

Jin, X. (2012). An Empirical Study on the Structure and Current Situation of Contemporary College Students' Employment Ability. Journal of Northeast Normal University (Philosophy and Social Science Edition), 6, 237-240.

Li, J. K. (2012). University Students Employment Ability of the Structure and Influencing Factors. China Youth Research, 11, 89-92.

Li, Y. (2016). Educational Reform, "Supply Side” Is the Key. http://theory.people.com.cn/n1/2016/0114/c40531-28050932.html, 2016-1-14.

Liu, Y. R. (2015). Should Also Pay Attention to the "Supply Side" Reform of Higher Education. China Education News, 2015-12-14(9).

Shi, Q. H., \& Wen, J. (2012). The Employability of Chinese College Students - An Analysis of Self-Evaluation Based on the Survey of Students' Intelligence. Peking University Education Review, 1, 48-60.

Song, Z. F., \& Song, H. L. (2012). Analysis of Characteristics Based on Content Analysis. Intelligence Science, 1, 964-966.

Wang, H. J., Peng, A. et al. (2012). Management (pp. 117-118). Beijing: Peking University Press.

Zhang, Y. Z. (2012). Research on Career Management of Undergraduates Based on Background Action Theory. Educational Exploration, 8, 78-80. 